Article

\title{
Solid Tellurite Optical Fiber Based on Stack-and-Draw Method for Mid-Infrared Supercontinuum Generation
}

\author{
Christopher Dunn ${ }^{1}$, Fanting Kong ${ }^{2}$, Guancheng Gu ${ }^{2}$, Thomas Wade Hawkins ${ }^{2}$, \\ Maxwell Jones ${ }^{1}$, Joshua Parsons ${ }^{2}$, Andrew Runnion ${ }^{2}$, Monica Tamara Kalichevsky-Dong ${ }^{2}$, \\ Reza Salem ${ }^{3}$, Dongfeng Liu ${ }^{3}$, David Gardner ${ }^{3}$, Peter Fendel ${ }^{3}$, Ron Synowicki ${ }^{4}$, Eric Cheung ${ }^{5}$, \\ Jean-Thomas Gomes ${ }^{6}$, Laure Lavoute ${ }^{6}$, Dmitry Gaponov ${ }^{6}$ iD, Sébastien Février ${ }^{7}$ and \\ Liang Dong ${ }^{2, *}$ \\ 1 Coherent I Nufern, 7 Airport Park Road, East Granby, CT 06026, USA; cddunn@g.clemson.edu (C.D.); \\ mjones@nufern.com (M.J.) \\ 2 ECE/COMSET, Clemson University, 91 Technology Drive, Anderson, SC 29625, USA; \\ fantink@clemson.edu (F.K.); ggu@g.clemson.edu (G.G.); hawkin2@clemson.edu (T.W.H.); \\ parson2@clemson.edu (J.P.); arunnio@g.clemson.edu (A.R.); mkalich@clemson.edu (M.T.K.-D.) \\ 3 Thorlabs Inc., 56 Sparta Avenue, Newton, NJ 07860, USA; rsalem@thorlabs.com (R.S.); \\ dliu2@thorlabs.com (D.L.); dgardner@thorlabs.com (D.G.); pfendel@thorlabs.com (P.F.) \\ 4 J.A. Woollam, 645 M Street, Suite 102, Lincoln, NE 68508, USA; rsynowicki@jawoollam.com \\ 5 Northrop Grumman Aerospace Systems, One Space Park R1/1184, Redonda Beach, CA 90278, USA; \\ eric.cheung@ngc.com \\ 6 Novae, ZA Bel Air, 87700 Saint Martin le Vieux, France; jt.gomes@novae-laser.com (J.-T.G.); \\ 1.lavoute@novae-laser.com (L.L.); d.gaponov@novae-laser.com (D.G.) \\ 7 University of Limoges, CNRS, XLIM, UMR 7252, 87000 Limoges, France; sebastien.fevrier@unilim.fr \\ * Correspondence: dong4@clemson.edu; Tel.: +1-864-656-5915
}

Academic Editor: Stephen C. Bondy

Received: 2 August 2017; Accepted: 18 September 2017; Published: 25 September 2017

\begin{abstract}
Broadband, high-power mid-infrared (mid-IR) sources are critical for many applications. Compared to alternatives such as fluorides and chalcogenides, tellurite fibers are more robust and can handle much higher power. Tellurite fibers also have high nonlinearity and a material zero dispersion close to $2 \mu \mathrm{m}$, making them ideal for nonlinear processes pumped by Tm-doped silica fiber lasers. In this work, we have demonstrated solid tellurite fibers fabricated by a stack-and-draw process and investigated their potential for broadband mid-IR supercontinuum generation. We have identified that fibers with low dispersion are beneficial and that low residual hydroxyl $(\mathrm{OH})$ is critical for broadband mid-IR supercontinuum generation in tellurite fibers pumped at $\sim 2 \mu \mathrm{m}$.
\end{abstract}

Keywords: fiber design and fabrication; supercontinuum generation; nonlinear optical materials; nonlinear optics; tellurite

\section{Introduction}

Mid-IR (MIR) sources are critical for a wide range of applications from identification of molecular species to countermeasures against missile attacks [1]. Broad bandwidth and high-power are required for improved capabilities in many of these applications. IR countermeasures are a significant and growing area of research. Currently, narrow-linewidth lasers are used to disrupt tracking signals. Wave-skipping techniques continue to improve to avoid countermeasures, rendering them less effective. There is, consequently, a strong interest for broadband, bright sources capable of covering the wavelength range from $2 \mu \mathrm{m}$ to $5 \mu \mathrm{m}$. Supercontinuum source is a promising technology for 
these applications. In addition to high MIR transmission, the optical fibers also need to have high nonlinearity and desired dispersion in this case.

Thulium (Tm)-doped mode locked fibers at $\sim 2 \mu \mathrm{m}$ are an ideal pump source for nonlinear conversion to broadband MIR. Tm-doped fibers are conveniently located close to the MIR wavelengths and can be produced robustly with mature silica fiber technology. Recently, kW-level continuous waveform (CW) Tm-doped fiber lasers (Nufern, East Granby, CT, USA) have been demonstrated due to the efficient two-for-one process, which enables the use of high-power diodes at $~ 795 \mathrm{~nm}$ as pumps [2]. Tm-doped fiber lasers can therefore provide a path for potential average power scaling to hundreds of watts for MIR sources.

MIR fibers fabricated from heavy metal fluorides and chalcogenides typically have poor physical strength and can degrade over time. These significant reliability issues have been a major barrier in using these fibers for practical applications [3]. Also, heavy metal fluorides exhibit low nonlinearity [4]. Chalcogenides have much higher nonlinearity than tellurite, but their material zero-dispersion wavelength (ZDW) is substantially far away from $2 \mu \mathrm{m}$, making them unsuitable to be pumped by a Tm-doped fiber laser, unless suspended-core design with strong waveguide dispersion is used [5]. There have been some recent developments in using highly germanium-doped silica fibers for supercontinuum generations [6,7]. The strong phonon absorption of silica, however, limits their applications to below $3 \mu \mathrm{m}$.

Tellurite glasses are heavy metal oxides, which are strong and chemically resistant. They have the capability to handle much greater powers, making them suitable for high-power operation. Tellurite glass also has over an order of magnitude higher nonlinearity than heavy metal fluorides; as well as a material ZDW close to $2 \mu \mathrm{m}$. Tellurite fibers are therefore promising candidates for high-power supercontinuum generation pumped by Tm-doped fiber lasers [8]. Tellurite offers good transmission from the visible to $\sim 5 \mu \mathrm{m}$ and provides good glass stability for fiber drawing. Recent reports have shown tellurite fiber strength extending to $60 \mathrm{kpsi}$ [9] and significant progress in reducing hydroxyl ions within the glass [10] and fiber [11-14]. The $\mathrm{OH}$ content is down to $0.5 \mathrm{ppm}$ in [13,14].

In this work, we have demonstrated a novel stack-and-draw process for the fabrication of solid tellurite optical fibers without an outer tube. This process enables simple and flexible fabrication of fiber from only rods. Previously, micro-structured tellurite optical fibers were made using mechanical means, such as extrusion or preform drilling [15-21] and all-solid tellurite optical fibers were made by the rod-in-tube method or build-in-casting $[8,9,13,14,22-25]$. The new fabrication process reported in this work demonstrates a simple and flexible process with a reduced risk of contamination.

We have demonstrated all-solid tellurite fibers with this new stack-and-draw process and MIR supercontinuum generation in these tellurite fibers pumped by $\mathrm{Tm}$ fiber lasers. We have also identified some optimal fiber designs for efficient broadband MIR supercontinuum generation and issues for improvement, which are critical for high-power MIR supercontinuum generation.

\section{Materials and Design Issues}

Our tellurite glass was fabricated at Kigre Inc. using $99.999 \%$ pure materials and dry atmosphere. The details of related glass preparation are documented in [26]. Three glass rods with $\sim 1.75$ in diameter were produced (Figure 1). The base glass consists of $\sim 60 \mathrm{wt} \% \mathrm{TeO}_{2}, \sim 20 \mathrm{wt} \% \mathrm{ZnO}$, and $\sim 20 \mathrm{wt} \% \mathrm{BaO}$ (see [26] for more details). For the two doped preforms (erbium and lanthanum), $\sim 2 \mathrm{wt} \%$ erbium was added to the base glass for testing erbium-doped tellurite fiber lasers (beyond the scope of this work) and $\sim 5 \mathrm{wt} \%$ lanthanum was added to depress the refractive index so it can be used as the cladding glass in the fiber. Kigre Inc. (Hilton Head, SC, USA) has made tellurite glass of these large sizes for many years, a testament to the stability of the base tellurite glass.

The $5 \mathrm{wt} \%$ lanthanum-doped tellurite glass was initially intended as the cladding material for a fiber core made of either the base glass or the $2 \mathrm{wt} \%$ erbium-doped glass. It was the ideal choice because it does not have optical transitions in the visible or IR and exhibits a lower refractive index than the base glass and the erbium-doped glass. During the caning process, the lanthanum-doped 
glass, however, crystallized. The high lanthanum-doping at $5 \mathrm{wt} \%$ has reduced the glass stability for caning. Consequently, the erbium-doped tellurite was used instead as the cladding glass in this work. The erbium-doped glass has a smaller dopant concentration of $2 \mathrm{wt} \%$ and did not display crystallization. The erbium-doped glass does not have absorption bands above $1.7 \mu \mathrm{m}$; it is therefore sufficient for our mid-IR supercontinuum generation experiment.

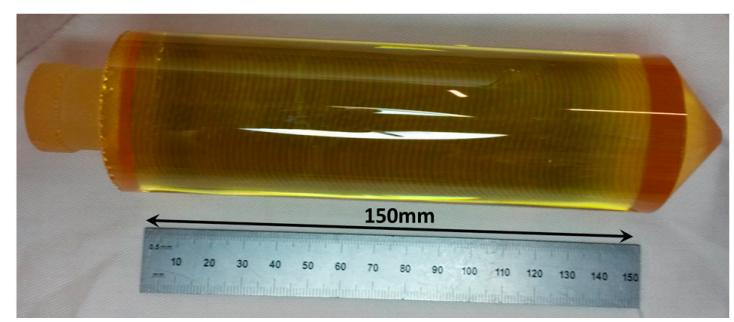

Figure 1. Tellurite bulk base glass fabricated by Kigre Inc.

The refractive indices of the core (base glass) and cladding glasses (erbium-doped and lanthanum-doped tellurite glasses) were measured using an ellipsometer at J.A. Woollam (Figure 2). The measured refractive indices were used to simulate the fiber dispersion, from which the fiber design was optimized.

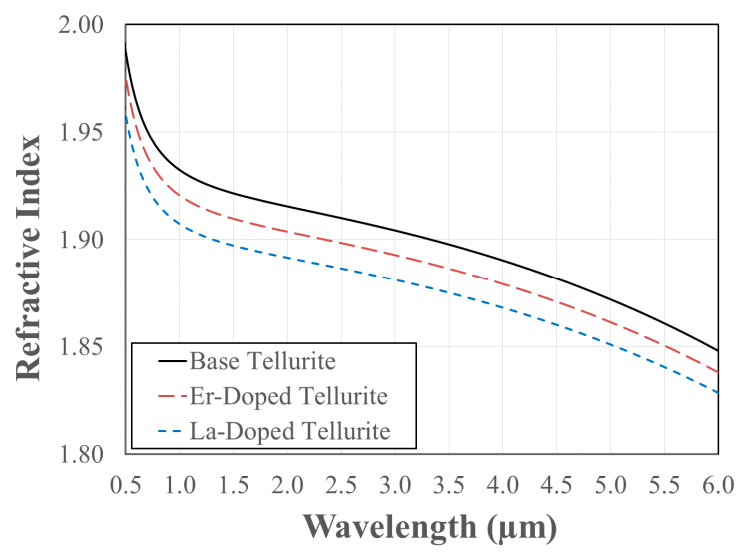

Figure 2. Refractive index curves of bulk tellurite base glass, Er-doped tellurite, and La-doped tellurite measured by ellipsometry.

\subsection{Fiber Dispersion Simulation}

The refractive index data obtained from the ellipsometry measurements (see Figure 2) was used for determining the fiber dispersion design using a homemade fiber mode solver, which is based on solving vector eigenvalue equations for circular boundaries similar to that described in [27]. Fiber dispersion can then be easily obtained from the wavelength-dependent propagation constant obtained from the mode solver. The fiber dispersion at various core diameters is simulated (Figure 3a), using the base glass as the core and Er-doped tellurite as cladding. This data helped guide us towards the correct fiber design, namely the correct core size. The ZDW versus core diameter is summarized in Figure 3b. With the current refractive index contrast between the core and cladding, the minimum achievable ZDW is $2.21 \mu \mathrm{m}$. For supercontinuum generation, it is better to have the pump wavelength located near the ZDW and in the anomalous dispersion regime. In our case with a Tm-doped fiber laser pump, this implies a ZDW of $\sim 1.9 \mu \mathrm{m}$. This target is not achievable with the current cladding material and a lower cladding index is required to achieve this objective. A core diameter of $5 \mu \mathrm{m}$ was chosen because it provides the best compromise between a low ZDW and flattened dispersion (Figure 3a). Lower ZDW 
can be achieved with a lower cladding index, such as the La-cladding design (Figure 3c,d) and the air-cladding design (Figure 3e,f).
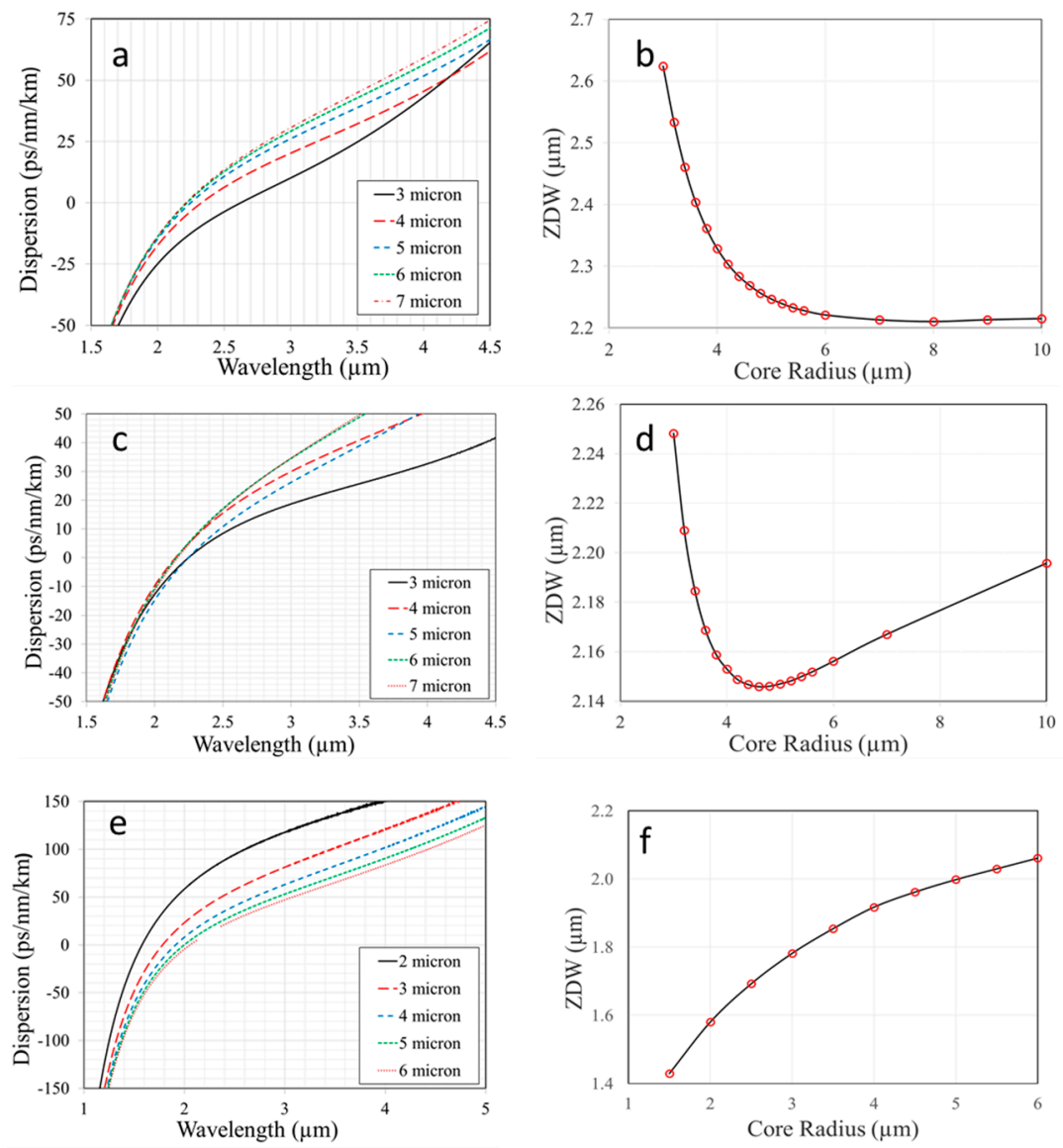

Figure 3. (a) Dispersion curve, of the current design (base tellurite core and Er-doped tellurite cladding), relative to wavelength; (b) zero-dispersion wavelength (ZDW) relative to core radius for the current design; (c) Dispersion curve of the design with base tellurite core and La-doped tellurite cladding, relative to wavelength; (d) ZDW relative to core radius for the La-cladding design; (e) Dispersion curve of the design with base tellurite core and air-clad design, relative to wavelength; (f) ZDW relative to core radius for the air-clad design (all legend refers to radius).

\subsection{Bulk Glass Loss}

For measuring the bulk glass loss, a base glass rod and an Er-doped tellurite glass rod were drawn down from $1.5 \mathrm{~mm}$ canes to $125 \mu \mathrm{m}$ fiber. These two fibers were coated with the standard acrylic coating, which has a much lower refractive index than that of tellurite glass and is able to provide optical guidance. Both fibers were very strong.

The fiber loss was measured on the Horiba iHR320 imaging spectrometer (Horiba Instruments Inc., Irvine, CA, USA), which consists of two broadband sources, a monochromator with multiple gratings, filters, and a range of detectors. It has a white light, tungsten source to cover $0.3 \mu \mathrm{m}-2 \mu \mathrm{m}$ and a Globar light source to cover $2 \mu \mathrm{m}-15 \mu \mathrm{m}$. The system also has four detectors: a thermoelectrically cooled silicon detector (Horiba Scientific, Edison, NJ, USA) for $0.2 \mu \mathrm{m}-1 \mu \mathrm{m}$; a liquid nitrogen cooled extended Indium Gallium Arsenide detector (Horiba Scientific, Edison, NJ, USA) for $1 \mu \mathrm{m}-1.9 \mu \mathrm{m}$; a liquid nitrogen cooled solid-state Indium Antimonide (InSb) detector (Horiba Scientific, Edison, NJ, USA) for $1 \mu \mathrm{m}-5.5 \mu \mathrm{m}$; and a liquid nitrogen cooled Mercury Cadmium Telluride detector (Horiba Scientific, Edison, NJ, USA) for $2 \mu \mathrm{m}-14 \mu \mathrm{m}$ coverage. 
The base glass and Er-doped tellurite glass fibers were both measured using the Globar lamp and the InSb liquid nitrogen cooled detector (Horiba Scientific, Edison, NJ, USA). Each fiber's transmission was measured from $2 \mu \mathrm{m}$ to $5 \mu \mathrm{m}$. The monochromator was used to scan each individual wavelength with a step size of $1 \mathrm{~nm}$. Filters were also used to eliminate higher-order grating reflections.

The base glass demonstrates a background loss in the fiber $<1 \mathrm{~dB} / \mathrm{m}$. Figure 4 shows that the loss of the base glass reaches a maximum at the water absorption peak of $18 \mathrm{~dB} / \mathrm{m}$. This loss value is relatively low compared to other tellurium-barium-zinc glass compositions. The Er-doped tellurite glass shows a higher background loss of $\sim 4 \mathrm{~dB} / \mathrm{m}$. The peak loss at the water absorption peak is also greater, maxing out at approximately $27 \mathrm{~dB} / \mathrm{m}$.

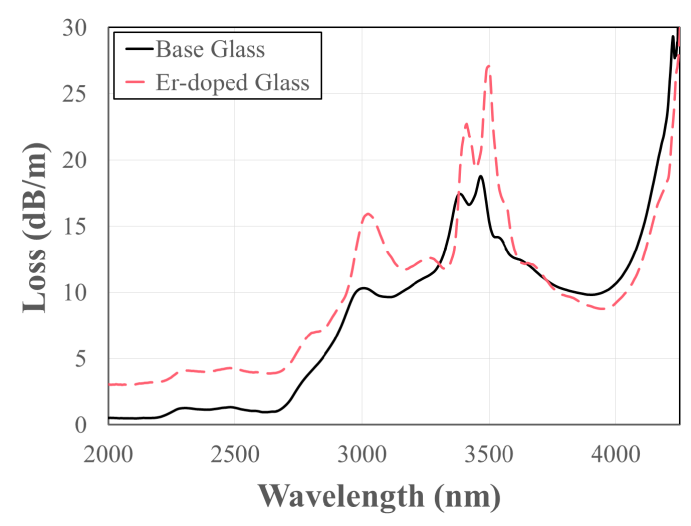

Figure 4. Measured fiber loss of the base tellurite glass and the Er-doped tellurite glass.

\section{Fiber Fabrication}

The first micro-structured tellurite optical fiber was made by extrusion, involving highly specialized equipment [18]. Traditionally, tellurite fibers are made using the rod-in-tube technique, or the build-in-casting method, where customized tubes must be made for each draw $[8,9,13,14,22-25]$. The stack-and-draw method of fabricating optical fibers is regularly used for photonic crystal structures [28]. Once the rods are drawn, it is easy to assemble preforms with varying core-to-clad ratios. The stack-and-draw approach also minimizes surface contact of glass with external materials, reducing potential contamination, unlike both the rod-in-tube fabrication process and extrusion. Stacking also allows for flexibility in preform design, as well as good repeatability compared to other methods. Normally, within the stack-and-draw method, an outer tube is used to prevent the stack from becoming unbundled. Due to the significant material and effort involved in creating a large customized tube for each preform, we have refined the technique and demonstrated for the first time that an outer tube is not necessary for tellurite fibers, further simplifying the process.

The procedure began with caning all the tellurite glass preforms (see Figure 1) to an outer diameter of $1.5 \mathrm{~mm}$. The base glass had the lowest draw temperature among the three preforms, and, as the dopant concentrations increased in the glass, the draw temperature also rose respectively. We drew over 100 rods with $800 \mathrm{~mm}$ in length for each glass, which could be used in multiple designs or iterations.

The all tellurite stack was fabricated by adding one base tellurite rod in the center of the stack, surrounded by several rows of erbium-doped glass rods. The stack was held together at the chucked end with an extended hexagonal clamp, while the drop end of the preform was held together tightly by stainless steel wire. During initial drop phase, the wires came down with the glass and the preform stayed fused for the remainder of the draw. The stack was drawn down to a $1.5 \mathrm{~mm}$ rod that was subsequently stacked in the center of yet another set of erbium-doped cladding glass to achieve the required core-to-cladding ratio. No outer clad tube was used in either fabrication step. Finally, the completed stack was drawn down to fiber $(125 \mu \mathrm{m})$ to achieve a core size of $5 \mu \mathrm{m}$. The final fiber cross section did not round out, but rather maintained the hexagonal shape that it began with, due to the low surface tension 
of tellurite glass (Figure 5). The resulting core size varied from $5 \mu \mathrm{m}$ to $7 \mu \mathrm{m}$. The fiber was coated with a standard acrylic coating. The fiber can withstand handling and has reasonable tensile strength.

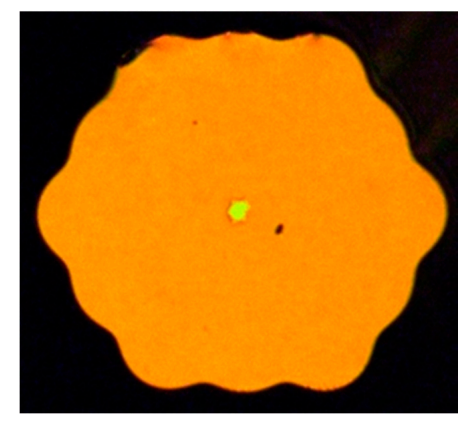

Figure 5. Cross section of tellurite fiber showing core and hexagonal shape $(125 \mu \mathrm{m})$.

\section{Fiber Characterization}

\subsection{Fiber Loss}

The fiber loss was measured on the Horiba iHR320 imaging spectrometer. The result given in Figure 6 shows a background loss of $\sim 7 \mathrm{~dB} / \mathrm{m}$ and also a broad absorption band form roughly $2.7 \mu \mathrm{m}-4 \mu \mathrm{m}$. This absorption can be attributed to the $\mathrm{OH}$ band and is caused by the incorporation of external moisture. The preform was dried at $200{ }^{\circ} \mathrm{C}$ with nitrogen gas flows of $5 \mathrm{~L} / \mathrm{min}$ (five times higher than during fiber drawing) in the furnace on the draw tower. The preform underwent three passes of moving the entire preform through the hot zone. These drying processes did not seem to be sufficient to remove all surface moisture introduced from the atmosphere in the stack.

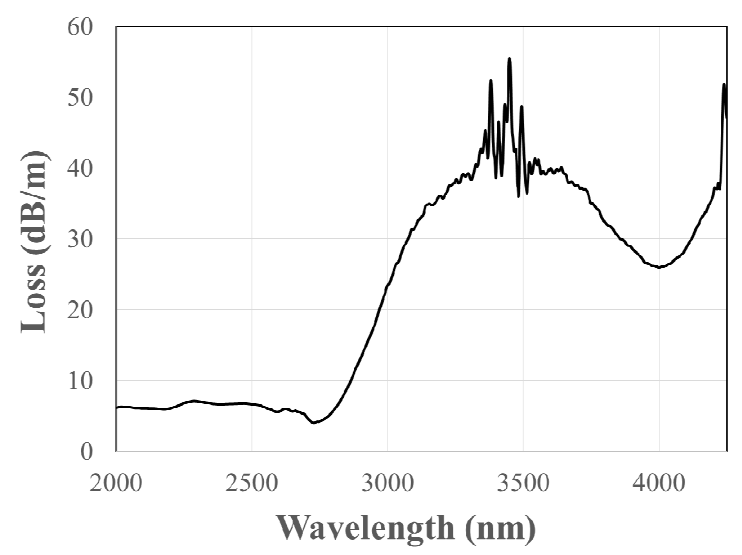

Figure 6. Fabricated fiber loss measured by the cutback method using the Horiba spectrometer with Indium Antimony detector.

\subsection{Fiber Dispersion}

Dispersion of a fiber is critical for efficient supercontinuum generation. By using a stack-and-draw method, fiber design can be controlled with ease. ZDW can be modified significantly by adjusting the core size of a micro-structured fiber [22].

Low coherence interferometry was used for the dispersion measurements [29]. A supercontinuum source with a single-mode delivery fiber from $650 \mathrm{~nm}$ to $2.3 \mu \mathrm{m}$ was used to cover a wide wavelength range. The input beam is split into two arms of the interferometer. The path length of the reference arm can be adjusted to coincide with the designated fiber length. The tellurite fiber was placed at the measurement arm. Beams from the two arms were combined and then passed through a 
monochromator for wavelength selection. The coherent interference was measured with a liquid nitrogen cooled $(\mathrm{InSb})$ detector. The reference arm path length was initially roughly chosen for the fiber length and was then finely adjusted to determine the exact location for coherent interference by a motorized linear translational stage. This was performed for a range of wavelengths to gather the delay-versus-wavelength data for the tellurite fiber. Due to the erbium-doped nature of the cladding, data collection near $1 \mu \mathrm{m}$ and between $1.4 \mu \mathrm{m}$ and $1.6 \mu \mathrm{m}$ was not possible due to erbium absorption. A polynomial fit was first performed on the delay-versus-wavelength data. The dispersion data can then be obtained from the polynomial fit by taking a simple derivative. The measured dispersion is close to the simulation (see Figure 7). The measured ZDW is $\sim 2.26 \mu \mathrm{m}$.

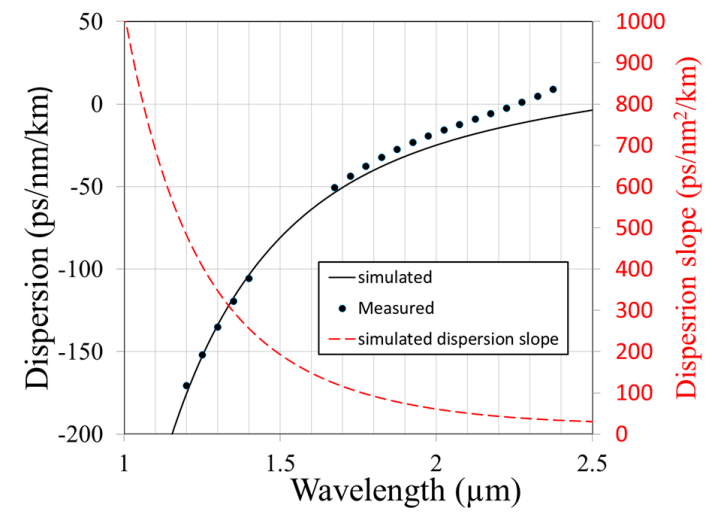

Figure 7. Fiber dispersion measured by low-coherence interferometry (dots) and simulated fiber dispersion (line).

\section{Supercontinuum Generation}

First, the seed oscillator wavelength and the amplifier dispersion of a Thorlabs Tm mode-locked laser (Thorlabs Inc., Newton, NJ, USA) were adjusted in order to determine the optimal conditions that maximize the supercontinuum spectrum in a tellurite fiber sample. The next step was to test for the ideal length of fiber that balanced nonlinear effects and fiber loss. The length decided upon was $60 \mathrm{~mm}$ for the tellurite fiber. The pump laser provided a center wavelength of $1.949 \mu \mathrm{m}$, a pulse duration of $52 \mathrm{fs}$, an average power of $570 \mathrm{~mW}$, a repetition rate of $50 \mathrm{MHz}$ and an estimated peak power of $200 \mathrm{~kW}$. Approximately $1000 \mathrm{~nm}$ of spectral broadening (Figure 8) was measured. Although the laser's central wavelength is over $300 \mathrm{~nm}$ from the ZDW, we were still able to obtain supercontinuum generation from $1.6 \mu \mathrm{m}$ to $2.6 \mu \mathrm{m}$.

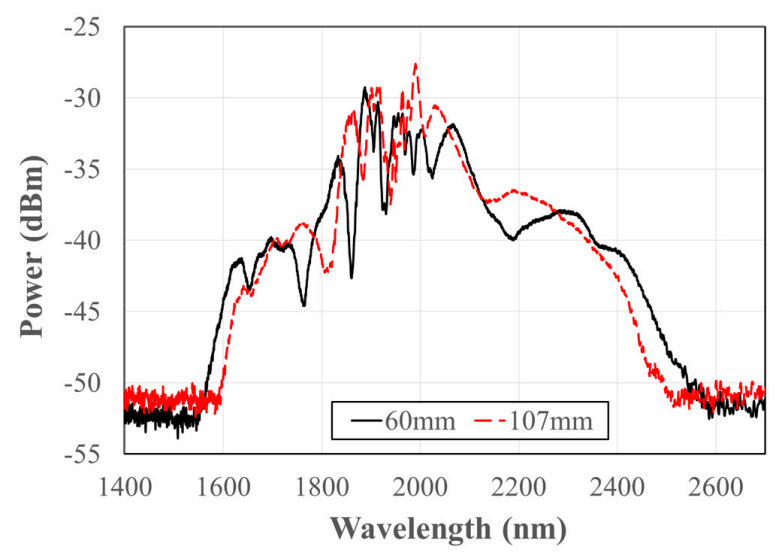

Figure 8. Supercontinuum at fiber lengths of $60 \mathrm{~mm}$ and $107 \mathrm{~mm}$. 
A simulation was conducted for this fiber using the code in [30]. An estimated peak power of $20 \mathrm{~kW}$ was used due to loss in launch optics and launch efficiency. The nonlinear index $\left(\mathrm{n}_{2}\right)$ used was $2.5 \times 10^{-19} \mathrm{~m}^{2} / \mathrm{W}$ [25]. Raman effects were simulated using the data for $\mathrm{TeO}_{2}-\mathrm{B}_{2} \mathrm{O}_{3}-\mathrm{ZnO}-\mathrm{Na}_{2} \mathrm{O}$ in [31], which provides a good approximation for our core glass. The dispersion used was from simulated dispersion data $\left(\beta_{2}=0.057575 \mathrm{ps}^{2} / \mathrm{m}, \beta_{3}=1.607 \times 10^{-4} \mathrm{ps}^{3} / \mathrm{m}, \beta_{4}=-2.41 \times 10^{-7} \mathrm{ps}^{4} / \mathrm{m}\right)$. Due to the constraint of the current program, we cannot use a wavelength-dependent nonlinear coefficient or loss. The constant nonlinear coefficient $\gamma$ of $0.020951 / \mathrm{m} / \mathrm{W}$ and loss of $6 \mathrm{~dB} / \mathrm{m}$ was used in the simulation. These constraints can be removed in the future to better estimate the supercontinuum generation.

The simulated supercontinuum is shown in Figure 9a and is very close to the measured supercontinuum for $60 \mathrm{~mm}$ and $107 \mathrm{~mm}$ long fibers. Since the pump wavelength is in the normal dispersion regime, most spectral broadening occurs initially from the self-phase modulation (SPM). The tellurite fiber's high nonlinearity makes SPM very efficient. The clear cut-off on the short wavelength side in the measurement shown in Figure 8 is due to erbium absorption in the cladding and increasing normal dispersion at the shorter wavelengths. Soliton formation and related wavelength shifts can also be observed in the anomalous regime $(>2.3 \mu \mathrm{m})$. The simulation was also performed for $100 \mathrm{~kW}$ peak power (Figure 9b), which shows that a significantly broader supercontinuum could be achieved at higher powers. Multiple soliton formations in the anomalous regime can be observed in this case above $2.3 \mu \mathrm{m}$.
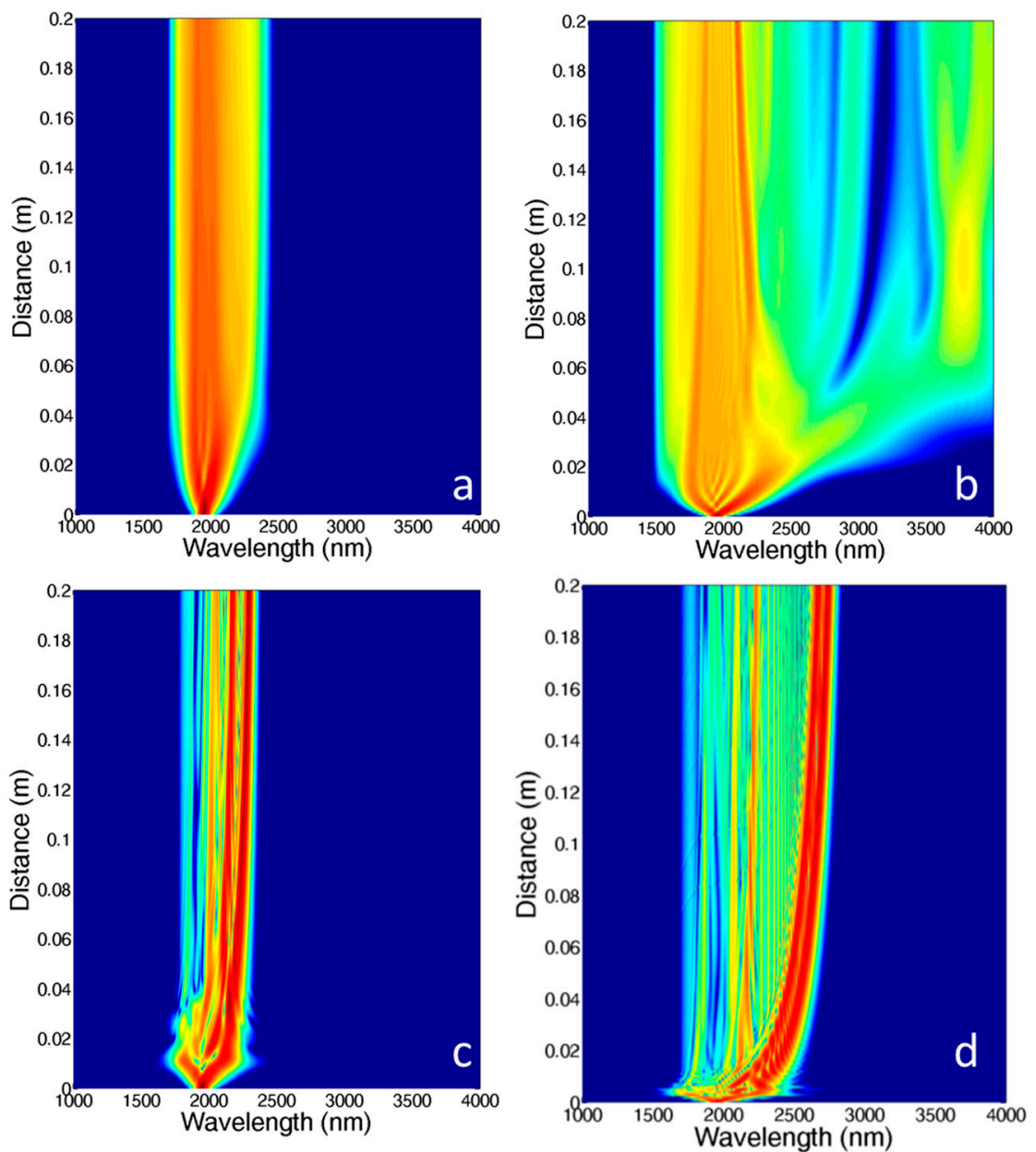

Figure 9. Simulated supercontinuum generation with constant loss at $6 \mathrm{~dB} / \mathrm{m}$ and with: (a) Current design at $20 \mathrm{~kW}$ peak power; (b) Current design at $100 \mathrm{~kW}$ peak power; (c) $4 \mu \mathrm{m}$-core Air-clad design at $20 \mathrm{~kW}$ peak power; (d) Air-clad design at $100 \mathrm{~kW}$ peak power. 
To better understand the wavelength dependence of the pump wavelength, we also tested $65 \mathrm{~mm}$ long fiber with a pump at longer wavelength (Novae, Brevity Lambda+). The central wavelength was at $2.1 \mu \mathrm{m}$ with a FWHM (full width at half maximum) pulse width of $93 \mathrm{fs}$, a repetition rate of $19.21 \mathrm{MHz}$, average power of $194 \mathrm{~mW}$, a peak power of $109 \mathrm{~kW}$ and PER > $15 \mathrm{~dB}$. The average power at the output of the tellurite fiber was $73 \mathrm{~mW}$ in this case. The normalized supercontinuum spectrum was compared to that with the $1.949 \mu \mathrm{m}$ pump in Figure 10 in linear scale. There is significant increase of spectral content at long wavelengths. The long wavelength power is, however, limited by the strong $\mathrm{OH}$ absorption in both cases. The longer wavelength pump clearly helped. The hydroxyl absorption loss of $\sim 55 \mathrm{~dB} / \mathrm{m}$ measured in our fiber is much higher than the record demonstrated in $[13,14]$. These results also identify the critical need for lowering $\mathrm{OH}$ loss.

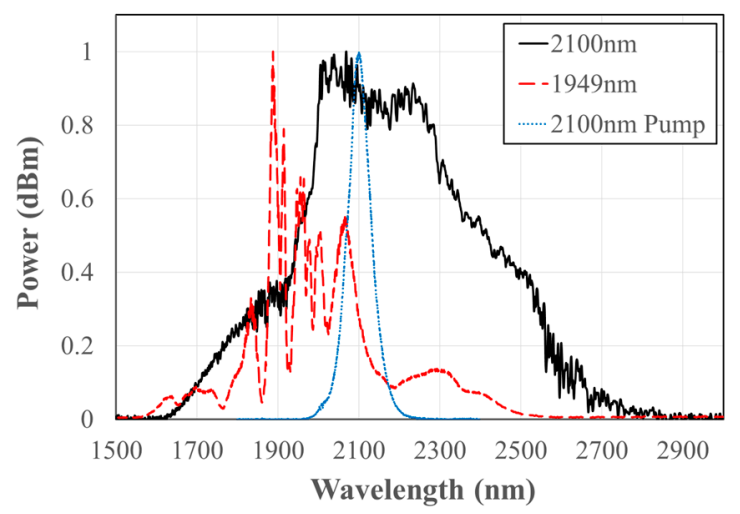

Figure 10. Comparison of normalized supercontinuum with the pumps at $1.949 \mu \mathrm{m}(60 \mathrm{~mm}$ fiber $)$ and $2.1 \mu \mathrm{m}$ (65 mm fiber). The normalized pump spectrum of the $2.1 \mu \mathrm{m}$ pump is also shown.

\section{Discussion}

For comparison, we further studied designs with cladding made of air to lower the ZDW using the $1.949 \mu \mathrm{m}$ pump. The increased refractive index contrast between core and cladding in this case leads to a much higher waveguide dispersion, which can be used to compensate for material dispersion. A much wider shift of the ZDW can be obtained in this case. For a design with the base glass as a core material and with air as cladding, the fiber dispersion was simulated and shown in Figure $3 \mathrm{e}$ for a range of core diameters. Shown within Figure 3f, a much broader range of ZDWs can be obtained by slight adjustments in core size. We executed the supercontinuum simulation for the air-clad design with a core diameter of $4 \mu \mathrm{m}$ at $20 \mathrm{~kW}$ and $100 \mathrm{~kW}$ peak powers, keeping all parameters the same, except the nonlinear coefficient $\gamma$ of $0.03611 / \mathrm{m} / \mathrm{W}$ and dispersion data $\left(\beta_{2}=-7.02 \times 10^{-3} \mathrm{ps}^{2} / \mathrm{m}\right.$, $\beta_{3}=2.95 \times 10^{-4} \mathrm{ps}^{3} / \mathrm{m}, \beta_{4}=-8.147 \times 10^{-5} \mathrm{ps}^{3} / \mathrm{m}$ ) (Figure $9 \mathrm{c}, \mathrm{d}$ ). This fiber design demonstrated a ZDW of $1.918 \mu \mathrm{m}$ just slightly below the pump wavelength at $1.949 \mu \mathrm{m}$ in the normal dispersion regime. It is surprising to see the simulated supercontinuum is not as broad as in the current fiber, especially at a $100 \mathrm{~kW}$ peak power. This is due to the significantly higher dispersion of this fiber in the anomalous dispersion regime (see Figure 3e). The simulation clearly demonstrates that lower dispersion is also beneficial in addition to the location of ZDW.

\section{Conclusions}

In conclusion, we have demonstrated a simple and flexible stack-and-draw fabrication process for an all-solid tellurite fiber. We have conducted both loss and absorption measurement of the fabricated tellurite fiber, demonstrating sufficiently low losses for supercontinuum generation. We have also demonstrated supercontinuum from $1.6 \mu \mathrm{m}$ to $2.8 \mu \mathrm{m}$ in the fabricated fiber and have shown that broad supercontinuum from $1.5 \mu \mathrm{m}$ to $4 \mu \mathrm{m}$ can be potentially generated at higher pump powers, providing the loss peak attributed to hydroxyl group is mitigated. We have further demonstrated that 
lower dispersion in the anomalous regime can be beneficial for efficient supercontinuum generation in cases where peak pump power is limited. This would imply that an all-solid design may be superior to a micro-structured design in this case. The improved broadening when pumped in the normal dispersion regime is due to the rapid SPM spectral broadening because of the high nonlinearity in tellurite fibers. This leads to significant power in the anomalous dispersion regime after only a short propagation. This work also demonstrates the critical need to lower $\mathrm{OH}$ for MIR supercontinuum generation in tellurite fibers.

Author Contributions: Christopher Dunn was involved in all phases of this work and performed a majority of the work. Fanting Kong and Guancheng Gu assisted in fiber characterizations. Thomas Wade Hawkins, Maxwell Jones and Joshua Parsons assisted in the fiber fabrication. Andrew Runnion wrote the simulation code. Monica Tamara Kalichevsky-Dong performed some of the characterizations. Ron Synowicki performed ellipsometry measurements on the tellurite glass. Reza Salem, Dongfeng Liu, David Gardner, Peter Fendel, Jean-Thomas Gomes, Laure Lavoute, Dmitry Gaponov and Sébastien Février assisted and performed the super-continuum generation measurements. Eric Cheung and Liang Dong helped to develop the project plan and contributed towards many of the ideas.

Conflicts of Interest: The authors declare no conflict of interest.

\section{References}

1. Razeghi, M.; Slivken, S.; Bai, Y.; Darvish, R. The Quantum Cascade Laser: A Versatile and Powerful Tool. Opt. Photonics News 2008, 19, 42-47. [CrossRef]

2. Carter, A.; Samson, B.; Tankala, K. Thulium doped fiber forms kilowatt-class laser. Laser Focus World $2009,45,51$.

3. Mouawad, O.; Strutynski, C.; Picot-Clémente, J.; Désévédavy, F.; Gadret, G.; Jules, J.C.; Smektala, F. Optical aging behaviour naturally induced on $\mathrm{As}_{2} \mathrm{~S}_{3}$ microstructured optical fibres. Opt. Mater. Express 2014, 4, 2190-2203. [CrossRef]

4. $\quad$ Ettabib, M.A.; Hammani, K.; Feng, X.; Belal, M.; Shi, J.; Bogris, A.; Kapsalis, A.; Syvridis, D.; Richardson, D.J.; Petropoulos, P. Highly Nonlinear Tellurite Glass Fiber for Broadband Applications. In Proceedings of the Optical Fiber Communication Conference, San Francisco, CA, USA, 9-13 March 2014.

5. Anashkina, E.A.; Shiryaev, V.S.; Koptev, M.Y.; Stepanov, B.S.; Muravyev, S.V. Development of As-Se tapered suspended-core fibers for ultra-broadband mid-IR wavelength conversion. J. Non-Cryst. Solids 2017, in press. [CrossRef]

6. Zhang, M.; Kelleher, E.J.R.; Runcorn, T.H.; Mashinsky, V.M.; Medvedkov, O.I.; Dianov, E.M.; Popa, D.; Milana, S.; Hasan, T.; Sun, A.; et al. Mid-infrared Raman-soliton continuum pumped by a nanotube-mode-locked sub-picosecond Tmdoped MOPFA. Opt. Express 2013, 21, 23261-23271. [CrossRef] [PubMed]

7. Jain, D.; Sidharthan, R.; Moselund, P.M.; Yoo, S.; Ho, D.; Bang, O. Record power, ultra-broadband supercontinuum source based on highly $\mathrm{GeO}_{2}$ doped silica fiber. Opt. Express 2016, 24, 26667-26677. [CrossRef] [PubMed]

8. Rhonehouse, D.; Zong, J.; Nguyen, D.; Thapa, R.; Wiersma, K.; Smith, C.; Chavez-Pirson, A. Low loss, wide transparency, robust tellurite glass fibers for mid-IR $(2-5 \mu \mathrm{m})$ applications. Proc. SPIE 2013, 8898, 88980D.

9. Thapa, R.; Rhonehouse, D.; Nguyen, D.; Wiersma, K.; Smith, C.; Zong, J.; Chavez-Pirson, A. Mid-IR supercontinuum generation in ultra-low loss, dispersion-zero shifted tellurite glass fiber with extended coverage beyond $4.5 \mu \mathrm{m}$. Proc. SPIE 2013, 8898, 889808.

10. Anashkina, E.A.; Andrianov, A.V.; Dorofeev, V.V.; Kim, A.V. Toward a mid-infrared femtosecond laser system with suspended-core tungstate-tellurite glass fibers. Appl. Opt. 2016, 55, 4522-4530. [CrossRef] [PubMed]

11. Savelii, I.; Desevedavy, F.; Jules, J.; Gadret, G.; Fatome, J.; Kibler, B.; Kawashima, H.; Ohishi, Y.; Smektala, F. Management of $\mathrm{OH}$ absorption in tellurite optical fibers and related supercontinuum generation. Opt. Mater. 2013, 35, 1595-1599. [CrossRef]

12. Cheng, T.; Zhang, L.; Xue, X.; Deng, D.; Suzuki, T.; Ohishi, Y. Broadband cascaded four-wave mixing and supercontinuum generation in a tellurite microstructured optical fiber pumped at $2 \mu \mathrm{m}$. Opt. Express 2015, 23, 4125-4134. [CrossRef] [PubMed] 
13. Strutynski, C.; Picot-Clémente, J.; Lemière, A.; Froidevaux, P.; Désévédavy, F.; Gadret, G.; Jules, J.-C.; Kibler, B.; Smektala, F. Fabrication and characterization of step-index tellurite fibers with varying numerical aperture for near- and mid-infrared nonlinear optics. J. Opt. Soc. Am. B 2016, 33, D12-D18. [CrossRef]

14. Kedenburg, S.; Strutynski, C.; Kibler, B.; Froidevaux, P.; Désévédavy, F.; Gadret, G.; Jules, J.-C.; Steinle, T.; Mörz, F.; Steinmann, A.; et al. High repetition rate mid-infrared supercontinuum generation from 1.3 to $5.3 \mu \mathrm{m}$ in robust step-index tellurite fibers. J. Opt. Soc. Am. B 2017, 34, 601-607.

15. Savelii, I.; Jules, J.; Gadret, G.; Kibler, B.; Fatome, J.; El-Amraoui, M.; Manikandan, N.; Zheng, X.; Désévédavy, F.; Dudley, J.; et al. Suspended core tellurite glass optical fibers for infrared supercontinuum generation. Opt. Mater. 2011, 33, 1661-1666. [CrossRef]

16. Feng, X.; Loh, W.H.; Flanagan, J.C.; Camerlingo, A.; Dasgupta, S.; Petropoulos, P.; Horak, P.; Frampton, K.E.; White, N.M.; Price, J.H.; et al. Single-mode tellurite glass holey fiber with extremely large mode area for infrared nonlinear applications. Opt. Express 2008, 16, 13651-13656. [CrossRef] [PubMed]

17. Feng, X.; Monro, T.; Finazzi, V.; Moore, R.; Frampton, K.; Petropoulos, P.; Richardson, D.J. Extruded singlemode, high-nonlinearity, tellurite glass holey fibre. Electron. Lett. 2005, 41, 835-837. [CrossRef]

18. Kumar, V.V.R.K.; George, A.; Knight, J.C.; Russell, P. Tellurite photonic crystal fiber. Opt. Express 2003, 11, 2641-2645. [CrossRef] [PubMed]

19. Ebendorff-Heidepriem, H.; Kuan, K.; Oermann, M.; Knight, K.; Monro, T. Extruded tellurite glass and fibers with low $\mathrm{OH}$ content for mid-infrared applications. Opt. Mater. Express 2012, 2, 432-442. [CrossRef]

20. Domachuk, P.; Wolchover, N.; Cronin-Golomb, M.; Wang, A.; George, A.; Cordeiro, C.; Knight, J.C.; Omenetto, F. Over $4000 \mathrm{~nm}$ bandwidth of mid-IR supercontinuum generation in sub-centimeter segments of highly nonlinear tellurite PCFs. Opt. Express 2008, 16, 7161-7168. [CrossRef] [PubMed]

21. Lin, A.; Zhang, A.; Bushong, E.J.; Toulouse, J. Solid-core tellurite glass fiber for infrared and nonlinear applications. Opt. Express 2009, 17, 16716-16721. [CrossRef] [PubMed]

22. Ohishi, Y.; Qin, G.; Liao, M.; Yan, X.; Suzuki, T. Recent progress in tellurite fibers. In Proceedings of the 2010 Conference on (OFC/NFOEC) Collocated National Fiber Optic Engineers Conference Optical Fiber Communication Conference, San Diego, CA, USA, 21-25 March 2010.

23. Liao, M.; Chaudhari, C.; Qin, G.; Yan, X.; Suzuki, T.; Ohishi, Y. Tellurite microstructure fibers with small hexagonal core for supercontinuum generation. Opt. Express 2009, 17, 12174-12182. [CrossRef] [PubMed]

24. Liao, M.; Yan, X.; Qin, G.; Chaudhari, C.; Suzuki, T.; Ohishi, Y. A highly non-linear tellurite microstructure fiber with multi-ring holes for supercontinuum generation. Opt. Express 2009, 17, 15481-15490. [CrossRef] [PubMed]

25. Wang, J.S.; Vogel, E.M.; Snitzer, E. Tellurite glass: A new candidate for fiber devices. Opt. Mater. 1994, 3 , 187-203. [CrossRef]

26. Zhou, B.; Rapp, C.; Driver, J.; Myers, M.; Myers, J.; Goldstein, J.; Utano, R.; Gupta, S. Development of tellurium oxide and lead-bismuth oxide glasses for mid-wave infra-red transmission optics. Proc. SPIE 2013, $8626,86261 \mathrm{~F}$.

27. Dong, L. Formulation of a complex mode solver for arbitrary circular acoustic waveguide. J. Lightwave Technol. 2010, 28, 3162-3175.

28. Knight, J.C.; Birks, T.; Russell, P.; Atkin, D. All-silica single-mode photonic crystal fiber. Opt. Lett. 1996, 21, 1547-1549. [CrossRef] [PubMed]

29. Kong, F.; Gu, G.; Hawkins, T.W.; Parsons, J.; Jones, M.; Dunn, C.; Kalichevsky-Dong, M.T.; Palese, S.P.; Cheng, E.; Dong, L. Quantitative mode quality characterization of fibers with extremely large mode areas by matched white-light interferometry. Opt. Express 2014, 22, 14657-14665. [CrossRef] [PubMed]

30. Dudley, J.; Taylor, J. Supercontinuum Generation in Optical Fibers; Cambridge University Press: Cambridge, UK, 2010.

31. Yan, X.; Qin, G.; Liao, M.; Suzuki, T.; Ohishi, Y. Transient Raman response effects on the soliton self-frequency shift in tellurite microstructured optical fiber. J. Opt. Soc. Am. B 2011, 28, 1831-1836. [CrossRef]

(C) 2017 by the authors. Licensee MDPI, Basel, Switzerland. This article is an open access article distributed under the terms and conditions of the Creative Commons Attribution (CC BY) license (http:/ / creativecommons.org/licenses/by/4.0/). 